\title{
Interpretasi Fasies Pengendapan Formasi Tondo, Pulau Buton, Sulawesi Tenggara Berdasarkan Data Pemetaan Geologi dan Potensinya Sebagai Batuan Reservoir Minyakbumi
}

Fasies Deposition Interpretation of Tondo Formation, Buton Island, Southeast Sulawesi Based on Geological Mapping Data and Its Potential As a Hydrocarbon Reservoir

\author{
Yuniarti Yuskar \\ Jurusan Teknik Geologi Fakultas Teknik Universitas Islam Riau \\ Jl. Kaharuddin Nasution 113 Pekanbaru 28284 \\ yuni.uir@gmail.com
}

\begin{abstract}
Abstrak
Daerah penelitian berada di Pulau Buton Provinsi Sulawesi Tenggara. Fokus penelitian pada bagian selatan Pulau Buton yaitu daerah Gonda dan Sekitarnya. Secara geografis terletak antara $122^{\circ} 42^{\prime} 28^{\prime \prime} B T-122^{\circ} 48^{\prime} 00^{\prime \prime}$ BT dan 5 $25^{\prime} 28^{\prime \prime} L S-05^{\circ} 25^{\prime} 28^{\prime \prime} L S$. Penelitian ini bertujuan mengetahui stratigrafi dan fasies pengendapan pada Formasi Tondo. Formasi Tondo menarik untuk dipelajari karena merupakan reservoir utama pada Cekungan Buton. Metodologi yang digunakan yaitu penelitian lapangan dengan mengambil conto batuan yang kemudian dilakukan analisis laboratorium mikropaleontologi dan laboratorium petrografi. Selain itu digunakan juga data-data dari peneliti terdahulu sebagai penunjang dalam interpretasi geologi. Formasi Tondo pada daerah penelitian setara dengan Satuan batupasir kerikilan. Satuan ini tersusun oleh batupasir kerikilan, batupasir sisipan batulempung dan konglomerat yang didominasi oleh batupasir kerikilan. Umur Satuan ini berdasarkan analisis laboratorium mikropaleontologi yaitu berumur Miosen Akhir (N17 - N18). Formasi Tondo merupakan reservoi utama di daerah Buton memiliki porositas yang baik sekitar 8 hingga $25 \%$ dengan rata-rata $10 \%$ dan maksimum permeabilitas $172 \mathrm{mD}$. Sistem pengendapan pada batupasir kerikilan ini merupakan sistem pengendapan tuirbidit terlihat dari adanya campuran butiran kasar dan halus serta dipengaruhi oleh lingkungan laut terlihat dari batuan yang bersifat karbonatan. Batupasir kerikilan sampai konglomerat merupakan hasil pengendapan channel dilaut dalam.
\end{abstract}

kata kunci: Formasi Tondo, fasies, reservoir, Buton

\begin{abstract}
The study area is located on the island of Buton in Southeast Sulawesi Province. The focus of research are in the Gonda and surrounding areas, southern part of the island of Buton. Geographically located between $122^{\circ} 42^{\prime} 28^{\prime}$ 'E - $122^{\circ} 48^{\prime} 00^{\prime \prime}$ E and $5^{\circ} 25^{\prime} 28^{\prime \prime} S-05^{\circ}$ 25 ' 28 "S. This study focus on determining the stratigraphy and depositional facies in Tondo Formation. Tondo Formation has become a major reservoir on Buton Basin. and still has become one of interesting thing for further study. The methodology used for the research field are to take rock samples and performed laboratory analysis such as petrographic and
\end{abstract}


micropaleontology analysis. In addition, it is also used data from previous researchers for support new geological interpretation. Tondo formation is equivalent to gravelly sandstone unit. And this unit are composed by gravelly sandstone, mudstone layers interbedded with sandstone and conglomerate sandstone. The age of this formation based on analysis at mikropaleontology laboratory is Late Miocene ( N17 - N18 ). Tondo Formation has become major reservoir at Buton Basin due to good porosity about 8 to $25 \%$ with average of $10 \%$ and also good permeability about $172 \mathrm{mD}$. This gravelly sandstone interpreted on turbidite depositional system as seen from the mixture of coarse and fine of the sandstone and gravel, and also influenced by the marine environment that are calcareous. So, this gravelly to conglomerate sandstone interpreted as a channel deposit on deep marine deposition.

Keyword: Tondo Formation, facies, reservoir , Buton

\section{PENDAHULUAN}

Secara administratif, Pulau Buton termasuk kedalam Kabupaten Buton, Provinsi Sulawesi Tenggara. Pulau Buton merupakan salah satu daerah sebagai penghasil aspalt di Indonesia. Keberadaan asphalt merupakan suatu indikasi bahwa daerah tersebut memiliki akumulasi hidrokarbon yang tidak terperangkap, namun dengan analisis yang lebih dalam dengan melihat aspek startigrafi dan struktur didaerah tesebut diyakini bahwa Buton masih memiliki akumulasi minyakbumi yang bersifat ekonomis, terutama dibagian laut (offshore) sebelah barat dan selatannya (BP MIGAS, 2007).

Penelitian difokuskan pada Daerah Desa Gonda, Kecamatan Sorawolio, Kabupaten Buton, Provinsi Sulawesi Tenggara merupakan salah satu daerah di Indonesia yang memiliki proses geologi yang kompleks. Secara geografis, daerah penelitian terletak pada koordinat $122^{\circ} 42^{\prime} 28^{\prime \prime}$ BT $-122^{0} 48^{\prime} 00^{\prime \prime}$ BT dan $5^{0} 25^{\prime} 28^{\prime}$ ' LS - 50 $40^{\prime} 00^{\prime \prime}$ LS yang tercakup pada Peta Rupabumi Digital Indonesia Lembar 2210-33 Mambulu, Lembar 2210-34 Lapanda, Lembar 2210-61 Bau-Bau dan Lembar 2210-64 Pasarwajo yang diterbitkan oleh BAKOSURTANAL.

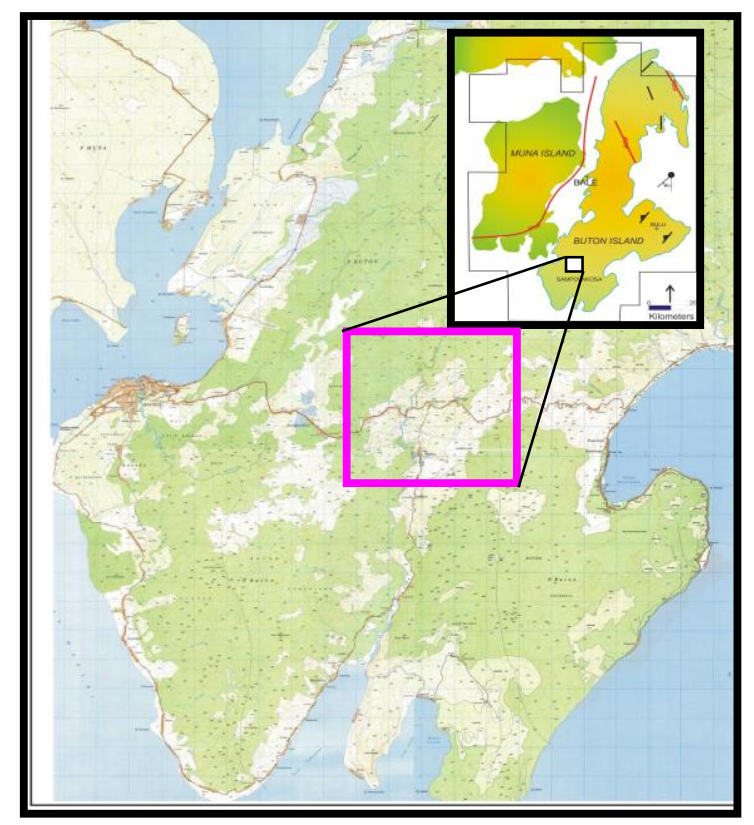

Gambar 1. Lokasi daerah penelitian 
Penelitian ini bertujuan untuk mengetahui lithostatigrafi dan fasies pengendapan Formasi Tondo dan aspek struktur yang mengontrol perangkap hidrokarbon, serta potensi Formasi Tondo sebagai batuan reservoir minyak dan gasbumi.

\section{TEKTONIK REGIONAL}

Wilayah Buton merupakan bagian dari fragmen mikrokontinen yang diantaranya terdiri dari Pulau Buton, Pulau Muna dan Pulau Tukang Besi yang saling berhubungan dan mempengaruhi ketika terjadi kolisi diantaranya. Berdasarkan Davidson, 1991 terdapat beberapa even tektonik yang mempengaruhi konfigurasi struktur geologi di Pulau Buton, diantaranya pre-rift, rift, drift, kolisi Neogen dengan dominasi struktur geologi yang terbentuk pada kolisi paling akhir.

Pada fase rifting diawali dengan pertumbuhan sesar ekstensional dan subsidence regional, kemudian membentuk rangkaian blok turun dalam sistem half graben yang disertai pula dengan pengangkatan, erosi dan vulkanisme lokal pada wilayah disekitarnya.

Fase drifting menyebabkan terpisahnya mikrokontinen dari kontinen utama (AustraliaPapua) dan mendukung terjadinya subsidence secara regional pada pulau Buton.

Fase tumbukan atau kolisi terjadi dalam dua periode, periode yang pertama adalah kolisi Miosen awal yang membentuk thin skinned thrust dan lipatan-lipatan di bagian selatan.
Kolisi mencapai titik maksimal pada Miosen Tengah menghasilkan pengangkatan dan sesarsesar naik lokal. Namur kolisi pertama ini tidak mempengaruhi Buton Utara sampai dengan Miosen Tengah, pada Akhir Miosen tengah ofiolit terobduksikan sebagai hasil dari kompresi maksimum. Melalui balanced cross section juga dapat diindikasikan efek dari kompresi maksimum pada kolisi I adalah terbentuknya cekungan-cekungan lokal sebagai akibat thrust-related shortening.

Kolisi oblique dari Buton dengan Muna juga menghasilkan pergerakan mendatar, yakni sesar sinistral Kioko sebagai sesar utama yang memisahkan konfigurasi cekungan dan sedimen-sedimen dibagian utara dan selatan. Pemendekan lokal sebagai akibat dari kolisi I ini lebih banyak terjadi di Buton Selatan.

Sementara Kolisi II terjadi antara mikrokontinen Buton dengan Tukang Besi yang mengakibatkan perubahan pola struktur yang signifikan dan deformasi, Hal ini disebabkan terjadinya penghimpitan zona subduksi sehingga menyebabkan akresi dari arah Barat (Pulau Buton). Efek awal dari kolisi ini terekam pada lapisan Pliosen akhir. Kolisi oblik dari 2 mikrokontinen dihasilkan dari pergerakan strike slip dan dip slip oleh sesarsesar curam dengan subsidence dan uplift lokal (Chamberlain et al, 1990).

Kompresi oblik dan sesar mendatar berlanjut hingga sekarang. Hal tersebut juga ditunjukkan melalui keadaan geomorfologi dan distribusi batugamping terumbu Pleistosen pada bagian 
selatan, yang mengindikasikan Buton Selatan lebih terangkat dan Buton Selatan mengalami subsidence (De Smet dkk, 1989).

Deformasi kuarter dan pengangkatan antara Buton Utara dan Selatan berhubungan dengan orientasi sistem patahan pre-pleistosen yang memiliki arah relatif tegak lurus terhadap arah utama tegasan pada kala pleistosen.

Di Buton Selatan terdapat pergerakan dip slip dan strike slip dengan pergerakan utama berupa dip slip diindikasikan oleh sesar-sesar naik berarah timur laut-barat daya yang terbentuk pada kala Miosen.

Sebagai gaya kompensasinya terbentuk pula cekungan pull apart transtensional. Sementara di Buton Utara deformasi utama diakomodasi oleh pergerakan sesar sinistral sistem sesar Kioko.

Gaya dan orientasi struktur yang ada sekarang menunjukkan keseluruhan mikrokontinen Buton berada pada zona transperssive strike slip. Relatif terhadap Tukang Besi dan Muna, mikrokontinen Buton lebih bergerak ke Utara. Antiklin En-Enchelon berarah timur laut dan berhubungan dengan sistem sesar mendatar. Di selat Buton terdapat indikasi reaktivasi zona paleo suture dengan pergerakan utama berupa sesar sinistral.

\section{STRATIGRAFI REGIONAL}

Berdasarkan Peta Geologi Regional Lembar Buton (N. Sikumbang, dkk, 1995), secara Regional Kabupaten Buton, Sulawesi Tenggara memiliki urutan stratigrafi dari tua ke muda berumur Pra-Trias hingga Resen yaitu Formasi Doole, Winto, Ogena, Rumu, Tobelo, Basalt, Diorit, Kompleks Ultrabasa Kapantoreh, Anggota Batugamping Tondo, Formasi Sampolakosa, Formasi Wapulaka, Alluvium.

Berdasarkan tektonostratigrafi startigrafi didaerah Buton dibagi menjadi empat yaitu Sedimen pre-rift, sedimen rift-drift, sedimen syn and post orogenenic dan sedimen recent orogenic.

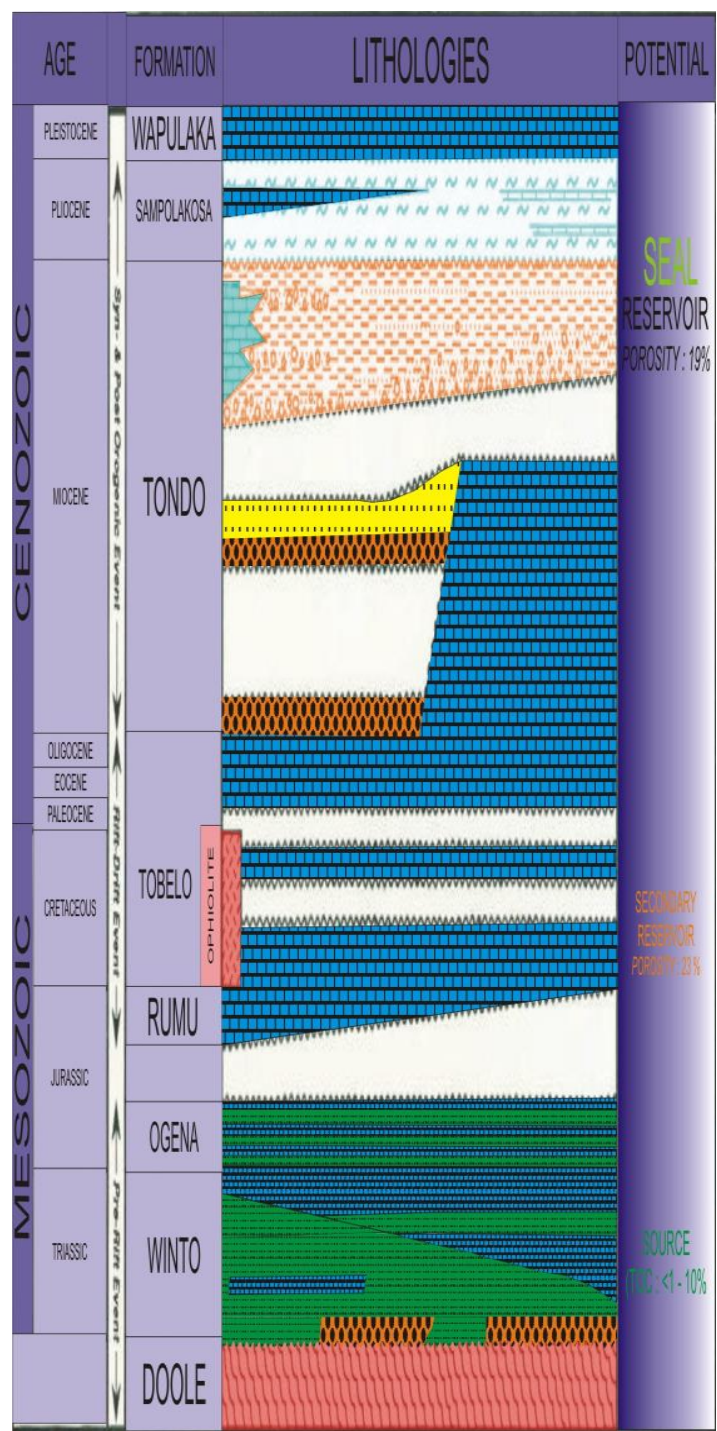


Gambar 2. Kolom Stratigrafi Regional Daerah

Buton (Davidson, 1991).

\section{METODOLOGI}

Adapun Metodologi yang dilakukan yaitu penelitian lapangan, penelitian laboratorim meliputi laboratorium paleontologi dan petrografi sserta analisis data di studio. Pengambilan data lapangan dilakukan pada 120 titik stasiun pengamatan. Analisis laboratorium paleontologi dilakukan pada 10 sampel batuan untuk mengetahui umur dan lingkungan pengendapan daerah penelitian. Analisis laboratorium petrografi dilakukan pada 10 sayatan tipis dari 10 stasiun pengamatan yang berguna untuk mengetahui jenis litologi yang tersebar didaerah penelitian. Selain itu juga dilakukan pengumpulan data sekunder yang berasal dari peneliti-peneliti terdahulu di daerah Buton

\section{HASIL PENELITIAN}

\section{Stratigrafi Daerah Penelitian}

Berdasarkan hasil penelitian dilapangan dan analisis di laboratorium maka diperoleh gambaran stratigrafi dan litologi penyusun dari yang paling tua ke yang muda yaitu Satuan Batuan Beku Peridotit, Satuan Batugamping Boundstone, Satuan Batupasir Kerikilan, Satuan Batulempung Karbonatan, Satuan Batugamping Grainstone. Satuan batuan tersebut bila dibandingkan dengan peta Geologi berdasarkan N. Sikumbang, dkk., 1995 memiliki kesetaraan yaitu Satuan Batuan
Peridotit setara dengan Kompleks Ultra Basa Kapantoreh, Satuan Batugamping Boundstone setra dengan Anggota Batugamping Formasi Tondo, Satuan Batupasir Kerikirilan setara dengan Formasi Tondo, Satuan Batulempung Karbonatan setara dengan Formasi Sampolakosa dan Satuan Batugamping Grainstone setara dengan Formasi Wapulaka. Fokus penelitian ini yaitu pada Satuan Batupasir Kerikilan yang setara dengan Formasi Tondo. Satuan ini tersusun oleh batupasir, batupasir sisipan batulempung dan konglomerat yang didominasi oleh batupasir kerikilan. Batupasir umumnya memiliki deskripsi yaitu Batupasir, kehijauan (lapuk), abu-abu(segar), berukuran butir menengah kasar, kemas terbuka, keras - dapat diremas, pemilahan buruk - sedang, membundar membundar tanggung, karbonatan, banyak terdapat butiran melayang berukuran kerikilan yang merupakan fragmen batuan yaitu batuan beku, batugamping, rijang, dan batupasir. Batupasir berukuran kerikilan ini tidak memiliki perlapisan yang jelas, dan biasanya terdapat dengan konglomerat dengan ciri butiran yang lebih halus. Dibeberapa stasiun ditemukan Batupasir sisipan batulempung yang memiliki deskripsi megaskopis yaitu berukuran, medium - kasar, coklat kehijauan (lapuk), abu-abu kehijauan (segar), pemilahan sedang - buruk, kemas terbuka, non karbonatan membundar - membundar tanggung, agak keras - dapat diremas. Batulempung menyerpih, abu-abu kemerahan 
(lapuk), abu-abu kecoklatan (segar), lunak dapat diremas, non - karbonatan.
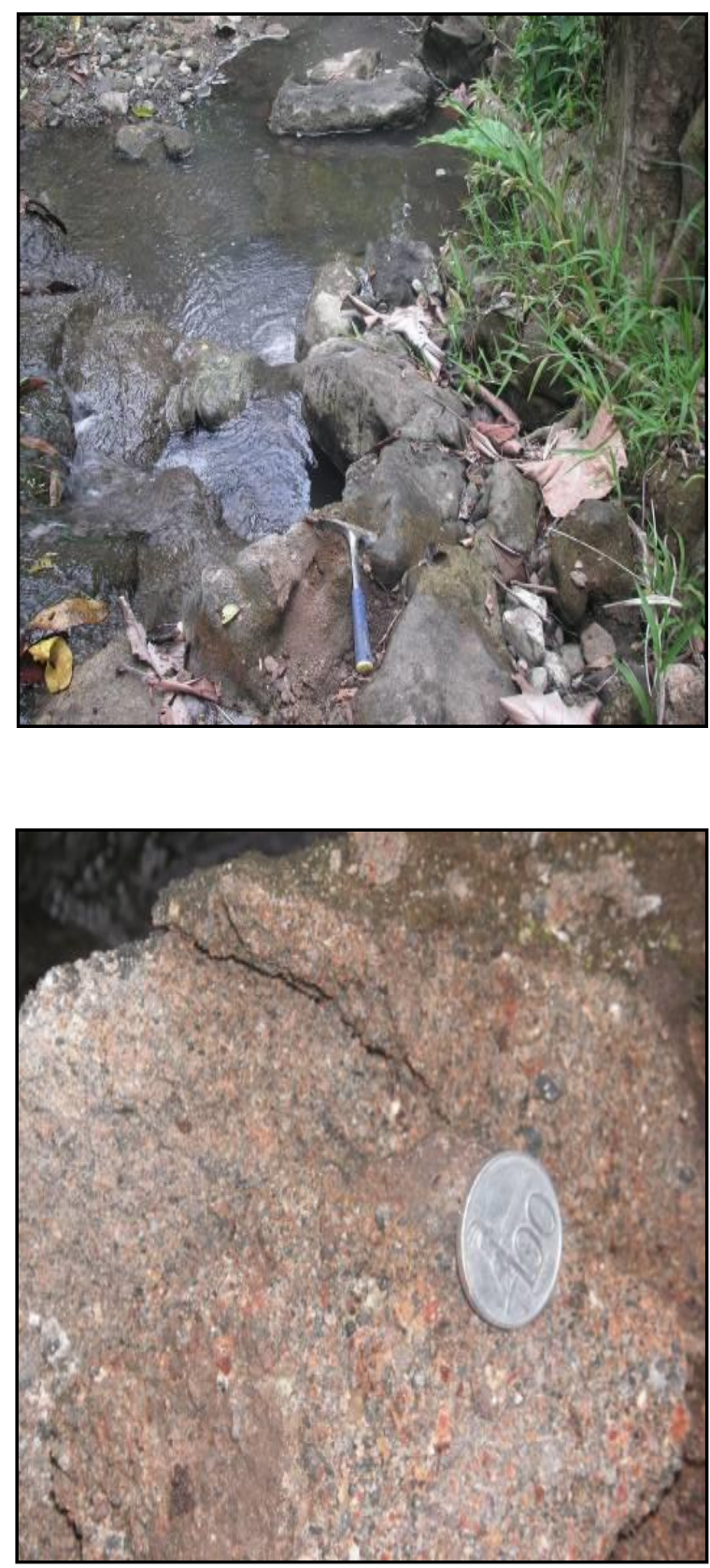

Gambar 3. Singkapan batupasir kerikilan pada stasiun Y-87

Konglomerat memiliki deskripsi megaskopis bewarna abu-abu kehitaman (lapuk), biru kehitaman (segar), kemas terbuka. konglomerat memiliki komponen batuan beku ulltrabasa (> 50\% berukuran rata-rata $5-15$ $\mathrm{cm})$, kuarsit $( \pm 20 \%$ berukuran rata-rata 2 $15 \mathrm{~cm})$, batupasir $( \pm 10 \%$ berukuran rata - rata 2 - $10 \mathrm{~cm})$, rijang bewarna merah, putih, (berukuran rata-rata 2-6 cm). Batuan beku afanitic, bewarna hitam (gelap), komponen yang berukuran kecil telah banyak terlapukkan sehingga bewarna merah. Batupasir, lower finesand - lower medium sand, banyak mineral mafic, menyudut - menyudut tanggung, keras - sangat keras, permeabiltas baik - scukup baik. Matriks karbonatan berukuran batupasir hitam kehijauan (lapuk) hitam kebiruan (segar) ukuran menengah - kasar, pemilahan buruk, kemas tertutup.

Secara mikroskopis satuan batupasir kerikilan memiliki deskripsi yaitu Sayatan berwarna abu-abu terang-kecoklatan, berbutir halussedang, membundar-menyudut tanggung, kemas tertutup, pemilahan jelek, terdiri dari feldspar, fragmen batuan dan mineral opaq, yang tertanam dalam matriks/semen gelas dan oksida besi. Deskripsi mineralogi yaitu feldspar (7\%): sebagai butiran, tidak berwarna, kristalin halus, bentuk memanjang, kembar albit, albit-kalsbad, relief sedang, indeks bias lebih besar dari media, sebagian tervitrifikasi menjadi gelas ; Fragmen batuan (60\%) :Tidak berwarna sampai abu-abu kecoklatankekuningan, berbutir halus-kasar , membundarmenyudut tanggung, terdiri dari fragmen batuan beku (34\%), bersifat serpentinite- 
peridotite, sebagian lagi merupakan fragmen batuan sedimen(26\%), terdiri dari fragmen batupasir dan batulempung; Oksida Besi (12\%):sebagai semen yang mengikat butiran dan matriks, bentuk tidak beraturan, warna coklat terang-kuning pucat; Gelas (16\%) : tidak berwarna, gelap pada posisi $\mathrm{x}$-nicol, merupakan hasil vitrifikasi; Mineral opaq (5\%) : Hitam, tidak tembus cahaya, membundar membundar tanggung, sebagai fragmen dalam matriks gelas dan mineral lempung. Berdasarkan deskripsi megaskopis dan mikroskopis nama batuan lithic greywacke (Pettijohn, 1975).

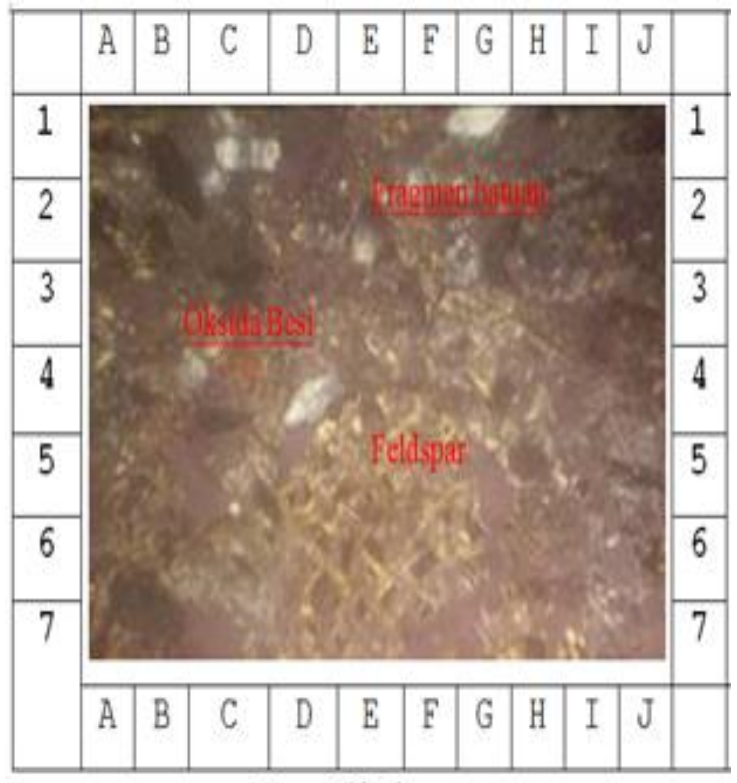

X-Nikol

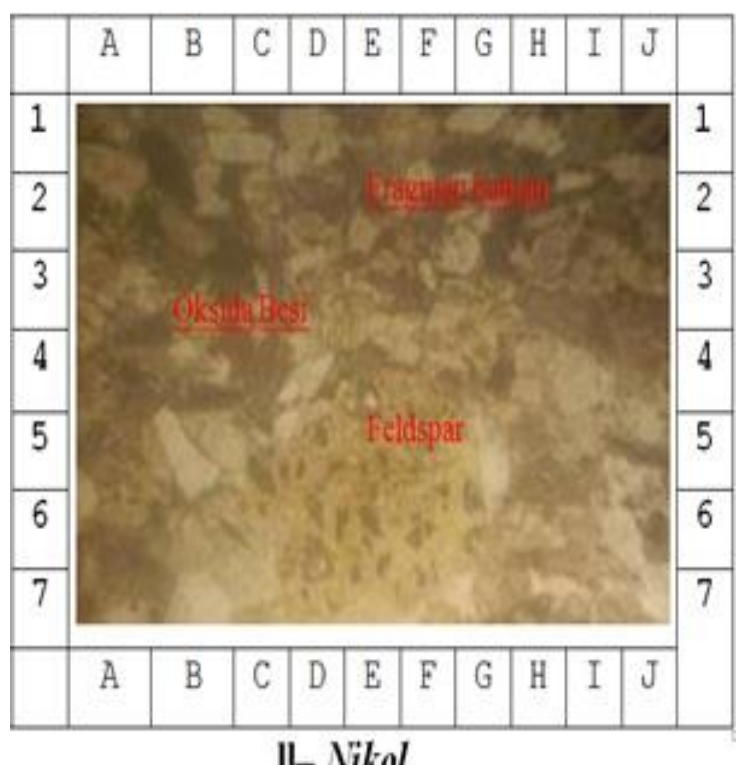

\section{I- Nikol}

Gambar 4. Sayatan Petrografi lithic greywacke di stasiun Y-56

\section{Interpretasi Umur dan Fasies Pengendapan \\ Formasi Tondo}

Penentuan umur dan lingkungan pengendapan pada satuan ini diperoleh dari kandungan fosil pada batulempung pada litologi batupasir sisipan batulempung. Adapun fosil - fosil dapat dilihat pada Tabel 1.

Dari fosil foraminifera bentonik dan planktonik tersebut dilakukan perhitungan untuk memperoleh rasio perbandingan planktonik dan bentonik yang digunakan dalam penentuan lingkungan pengendapan.

Rasio P/B $=\frac{53}{53+7} \times 100 \%=\mathbf{8 8 , 3 3 \%}$ 
Tabel 1. Fosil foraminifera Planktonik pada stasiun Y-52

\begin{tabular}{llc}
\hline No & Foraminifera Planktonik & Jumlah \\
\hline 1 & $\begin{array}{l}\text { Globorotalia tumida } \\
(\text { BRADY) }\end{array}$ & 8 \\
\hline 2 & $\begin{array}{l}\text { Orbulina universa } \\
\text { D'ORBIGNY }\end{array}$ & 6 \\
\hline 3 & Sphaeridinellopsis & 5 \\
& semirulina SCHWAGER & \\
\hline 4 & Globigerinoides trilobus & 10 \\
& (REUSS) & \\
\hline 5 & Globigerinoides immaturus & 3 \\
& LE ROY & \\
\hline 6 & Pulleniatina primalis & \\
& BANNER dan BLOW & 5 \\
\hline 7 & Globigerinoides extremus \\
& BOLLI & 5 \\
\hline 8 & Sphaeridinellopsis & 5 \\
& subdehiscus BLOW & \\
\hline 9 & Globorotalia plesietumida & \\
& BLOW dan BANNER & \\
\hline & Jumlah Total & \\
\hline
\end{tabular}

Tabel 2. Fosil Foraminifera Bentonik pada stasiun Y-52

\begin{tabular}{lll}
\hline No & Foraminifera Bentonik & Jumlah \\
\hline 1 & Ehrenkergina sp & 2 \\
\hline 2 & Cristellaria & 1 \\
\hline 3 & Robulus sp & 3 \\
\hline 4 & Siphonina bradyana & 1 \\
\hline & Jumlah Total & 7 \\
\hline
\end{tabular}

Berdasarkaninterpretasi hubungan pelagik rasio, kedalaman, dan lingkungan batimetri (Tipsword et al., 1966), Maka lingkungan pengendapan sampel adalah pada lingkungan Lower Slope dan lingkungan Neritik luar Batial tengah.

Dalam penentuan umur digunakan zonasi Blow dan fosil indeks, maka dari fosil - fosil yang ditemukan didapat kisaran umur relatif yaitu Miosen Akhir N17 - N18.

Sistem pengendapan pada batupasir kerikilan ini merupakan sistem pengendapan tuirbidit terlihat dari adanya campuran butiran kasar dan halus serta dipengaruhi oleh lingkungan laut terlihat dari batuan yang bersifat karbonatan. Batupasir kerikilan sampai konglomerat merupakan hasil pengendapan channel dilaut dalam. Hal ini didukung juga dengan adanya variasi jenis litologi di bagian barat atau bagian selatan dari satuan batupasir 
kerikilan ini yaitu keterdapatan lapisan batupasir masif (massive sandstone), batupasir halus berselang-seling dengan batulanau yang memiliki struktur sedimen pararel laminasi yang diinterpretasikan sebagai overbank deposit atau channel leeve system yang berada diisi channel.

\section{Formasi Tondo Sebagai Reservoir} MinyakBumi

Di daerah Buton banyak terdapat rembesan minyak, gas dan keberadaan aspal mencirikan adanya hidrokarbon didaerah tersebut. sistem petroleum yang terbentuk di Buton memungkin daerah tersebut untuk dieksplorasi lebih lanjut. Keterdapatan hidrokarbon ini berasal dari batuan induk yaitu Formasi Winto. Formasi Winto dengan litologi shale berumur Trias kaya akan sulfur, tipe Kerogen II dengan total organic content (TOC) 1-16\% (Tanjung, H, dkk 2007).

Reservoir utama di daerah Buton yaitu Formasi Tondo yang merupakan batupasir kerikilan memiliki porositas yang baik sekitar 8 hingga $25 \%$ dengan rata-rata $10 \%$ dan maksimum permeabilitas $172 \mathrm{mD}$. Formasi Tondo memiliki dua perangkap hidrokarbon yaitu perangkap struktur dan perangkat stratigrafi. Perangkap struktur berupa blok patahan dan antiklin sedangkan perangkap startigrafi berupa pinch-out yang merupakan perangkap yang potensial pada Formasi Tondo.
1. Formasi Tondo yang setara dengan Satuan Batupasir Kerikilan merupakan formasi yang diendapkan pada lingkungan laut dalam, yaitu pada lingkungan pengendapan turbidit.

2. Batupasir kerikilan ini diinterpretasikan sebagai endapan channel yang masuk kedalam sistem pengendapan laut dalam, hal ini terlihat dari campuran butiran kasar dan halus yang menjadi satu disertai dengan ditemukannya pecahan pecahan endapan karbonat.

3. Dari hasil analisa porositas bahwa formasi ini memiliki nilai $8-25 \%$ porositas dan permeabilitas maksismum yaitu $172 \mathrm{mD}$, maka formasi ini berpotensi untuk menjadi reservoir utama pada cekungan Buton ini.

\section{DAFTAR PUSTAKA}

Davidson, J.W. 1991. The Geology and Prospectivity of Buton Island, S.E. Sulawesi Indonesia. Proceeding IPA 20th, Jakarta.

Phleger, F.B. dan F.L. Palker. 1951. Ecology of Foraminifera in Northwest Gulf of Mexico. Geological Society of America, Bulletin, Memoir 46 part I.

Postuma, J.A. 1971. Manual of Plantonic Foraminifera. Erenier, The Haque, Amsterdam.

\section{KESIMPULAN}


Sikumbang, N, dkk. 1995. Peta geologi Lembar Buton. Pusat Penelitian dan Pengembangan Geologi, Bandung.
Tanjung, H, dkk. 2007. Trend of Petroleum Exploration in Buton: An Insight From Tectonic, Stratigraphic and Geochemical Aspect. Proceeding IPA 21th, Jakarta. 